\title{
Lonely Together: The Psychological Divide Due To Social Networking Sites
}

\author{
Aastha Dhingra ${ }^{1}$
}

\section{ABSTRACT:}

We live in a world full of judgment and competition, inescapably comparing ourselves and being compared to those around us. The types of actions users take and the kinds of information they are adding to their Facebook walls and profiles are a reflection of their identities. You are your Facebook, basically, and despite all its socialness, Facebook is a deeply personal medium.

The time spent earlier during a car ride to a daydream, or building fantasies during lunchtime at work, or those small breaks one took to gaze outside the window are now all time to connect with technology, reply to a text, log on to websites and check email or notifications. I feel robbed on my aloneness, to be rather a buzz of constant communication, that hinders my every moment, and there is always someone to reply to.

I finalized this topic because I wanted to explore the need of projection of an online identity of one's self and if it is the performance and the constant simulation that keeps us stimulated and addicted or is it the reflection of the real onto our screens, because some of us project and consume, idealized images through Facebook, and researchers have been trying to figure out how all this flawlessness affects us in the real world.

Keywords: Social Networking Sites, Self Esteem, Psychological Well Being, Lonely Together, Facebook

"I'm about to bake cookies for my boyfriend!" "I have 2 job interviews this week!" "I just had the most romantic night ever!"

Do any of these sentiments sound familiar to you? It's not a foreign concept that Facebook status updates may be geared toward all the positive occurrences in one's life. It's also likely that when some scroll through their news feeds, they're comparing these successes to their own lives.

${ }^{1}$ Director, AD Executive Training \& Coaching Pvt. Ltd. 
As if people did not already have enough things to worry about when they leave the house, the internet can do a good job of adding to social neurosis. Think about leaving the house looking your absolute best. Are people complementing your new haircut, are they craning their necks to see your wicked-cool mustache? How do you feel when you notice people not noticing you? I think everyone has gone out feeling like this at one point or another, and I believe that what you think people think of you has a lot of import into what you take your identity to be. But now people can form opinions of you without you ever even having to leave your house, from the second a person lays eyes on your profile picture they have an opinion of you formed.

I resisted when they told me it was the hottest thing ever, I resisted even when I was left out of conversations because I didn't know what they were talking about, I resisted being tagged or poked or looked at whenever one fancies it. I had my high and mighty reasons of not being pushed, just so that I belong, I did not want to be faced with dilemmas and people from my past, I was so comfortable with the idea that some people are left behind and we carry forward some for a reason. It was purposeless, non-constructive and I chose to be unavailable. And yet here I am with people in my friend list who aren't my friends, being poked or tagged, distributing hugs and kisses, hearts and love-you's to people I would not even want to see, jostling out of invitations for parties and coffees. I got addicted and I have seen my friends addiction towards social networking sites like facebook etc to the limit that my topic of study is to understand the powerful need that is being met by myself and a million other selves who are in the predicament that I'm in, I need to understand how that identity that I have created for my friends has taken on such an important, such an essential role in my life. When did people's value judgment become the notifications and highlights of my day?

When I 'like' comments and statements and I am told that a 45 more people also like this, do I then feel one with the world and more acceptable or is my uniqueness threatened? Am I seeking validation through Facebook and other social networking sites, of my actions and movements and creating performances of everyday ordinary events to make them more entertaining so that people comment or like me? Is the symbol then more important than what it symbolizes? We are fed with this simulated self as a better self and we lap it up.

I need to understand the powerful need that is being met by my self and a million other selves who are in the predicament that I'm in, I need to understand how that identity that I have created for my 487 and counting friends has taken on such an important, such an essential role in my life. When did people's value judgement become the notifications and highlights of my day? During this study, I explore the need of a projection of an online identity of one's self and the creation of this community as a mirror of the social order 'reality'. Is it the performance and the constant simulation that keeps us stimulated and addicted or is it the reflection of the real onto our screens. This made me think of a need of a perfect identity, of a human need to showcase only that which is best and acceptable. So, then is Facebook feeding into our narcissism?

Facebook now decides what the vital statistics of my personality are, what is important to share and what aspects can be ignored. The personality traits, likes, dislikes can even be manipulated 
to create who I want to be, rather than who I am. And then I guard my wall, my friend lists, my comments etc. to live up to the identity that I have created online.

People are beginning to realise that something is amiss and are beginning to think more about their needs and fantasies, wants and disappointments with their online identities. In humour, in satire, in parody, we often convey that which we are unable to formulate or admit to. During the course of this research I came across numerous such videos and texts that made fun of the constant connection and the 'friendships' that Facebook has to offer.

At the same time Facebook opens up avenues to compare your life with the way other's has turned out. One can stalk the achievers and popular people from their past and compare their lives with them to nitty gritty out aspects that would salvage a sense of achievement in one self. In real life, if you were to meet an acquaintance and discover their unhappy life, would you still gloat as much on your own small victories as opposed to them? In fact, how would such an encounter even be available to you without facebook? Does Facebook then turn us into objects that can be judged and compared against? It is feeding into my voyeurism and scarily enough knows what ticks me.

A blogger recently proclaimed how Facebook shall be the end of volition as we know it, because it will begin to read people so well such that it will give people better life choices than people can present themselves with.

Even as I write this and if you are reading this on a computer the chances of a Facebook window open in the background or a notification reaching your phone or computer device of any kind is very high. Every major website now has affiliations with Facebook to use its userbase or help user connect to that website through Facebook. It's almost like the internet's new face is Facebook, but also it permeates beyond, reaches our lives and changes us.

We all know how the definition of the word "friend" has been challenged by social media. Our circles have grown to include everyone from best buddies to co-workers, to kindergarten classmates and friends of friends of friends, to strangers. Connecting with this vast online community can topple our sense of self, according to Malkin. He says many 20 -somethings are telling him and his colleagues that they actually "hate" Facebook - even though they're on it a lot. When people go on to Facebook they're often crafting a persona - they're portraying themselves at their happiest. They're often choosing events that feel best to them and they're leaving out other things."

You can literally airbrush your pictures online for free. I know about it and, I've done this too. You upload your picture and you can take out all your little pimples and stuff to make it look like your skin is perfect, your hair is perfect. These picture-perfect images can be especially difficult for teenagers to grapple with because they're often hyper-conscious of measuring up to their peers. It's a tender and critical stage in life - a time for forming an understanding of who you are. It affects an individual deeply because part of the way we develop a strong sense of self and 


\section{Lonely Together: The Psychological Divide Due To Social Networking Sites}

identity is by being known and known by others - appreciated. They see who we are, and they value who we are, including our flaws.

I have seen and heard many people insisting that Facebook is just another website we are on, that there really isn't much going on behind the behaviour patterns we display online, that nothing much has changed about our interactions and communication patterns with friends. Facebook seems to have tapped into some needs of ours that we are either not fully aware of or are unwilling to explore further.

The textual nature of all conversation and excited Status shuffle, when someone writes their thoughts down, is more often than not that the articulation of the kind that has allowed for a more formulated thought and so I love these little updates about people whom I know, as if catching fleeting thoughts. So the moment you log onto facebook, it makes available in the news feed, so much of new data, information, thoughts, ideas, pictures, questions, that to one who is not used to the page, it is a mysterious array, a kaleidoscopic view of scattered ideas.

The peculiar dynamism that media seems to bring to human beings is long since being documented. However subtle or obviously man has evolved with media has been a topic of discussion for long. Since the printing press, the evolution of media and man with it has been rapid. More connectivity and now constant online communication has changed interactions and relationships and in changing the nature of these, in changing the other it has of course changed the self. As one tries to catch up in this fast paced change in technology and reach an understanding of the man as he stood in that split second before the scenario changes again, we can only realise that this is not going to stop but that should not stop our efforts at catching up.

There has been a substantial amount of work done on the media changing man in the past and the present, but for the purposes of the research and in keeping with how I am to arrive at the present only to note that it has become the past, I shall primarily focus the review of literature onto those texts only which highlight the change that has been brought out with the internet and in particular social networking. Also in order to build a base to what I have to say now, I shall review some other texts which are a window unto this work and have emerged from the theoretical background I am comfortable with hence, it is imperative I introduce them to the reader.

Sherry Turkle writes, "Technology proposes itself as the architect of out intimacies. It suggests substitutions that put the real on the run."7 Technology has begun catering to our needs of intimacies with just the right amount of contact, i.e. it allows for us to communicate via text, email and networking websites at our own time and convenience whereas telephonic conversations take real- time time and in this fast paced world that is too much to ask for. Also it solves another purpose of keeping things direct, simple and at bay, because one does not indulge in social intricate ettiquettes etc. on text, or as she writes, "We are lonely but fearful of intimacy. Technology offers friction free relationships that you can have without leaving your desk. it ties us up in its promise to free us. Thus, even when we are not at work, the experience if that of always of being always on call. 
Robert Jay Lifton writes In his essay, 'Protean Man' that, “one encounters in protean man what I would call strong ideological hunger. He is starved for ideas and feelings that can give coherence to his world, but here too his taste is for new combinations. While he is by no means without yearning for the absolute, what he finds most acceptable are images of a more fragmentary nature than those of the ideologies of the past; and these images, although limited and often fleeting, can have great influence upon his psychological life." The internet was a revolution for the protean man's psychological life then, for now the speed he craves can be satiated and his need for this constant exploration and experiment can be met by creating different identities online.

Winnicot in 'The capacity to be alone', also wrote, "The pathological alternative is a false life built in reactions to external stimuli." " Facebook is the 'external stimuli' most of us keep reacting to nowadays. Writer, poet K.T. Jong is quoted often as having said, "It is only when we silent the blaring sounds of our daily existence that we can finally hear the whispers of truth that life reveals to us, as it stands knocking on the doorsteps of our hearts."

Journalist Jose Vargas in 2010, Zuckerberg said the following: "Most of the information that we care about is things that are in our heads, right? Think about what we're doing when we use Facebook. We're creating digital versions of our relationships, activities, even our identities. We're turning parts of our lives into code." But its doing more, its changing how we see things, when we are on facebook we experience a sort of blurring of differences, boundaries and hierarchies that are applicable in the outside world.

Craig Malkin, Belmont-based clinical psychologist, finds that one in three respondents felt more dissatisfied with their own lives after spending time on the site. Viewing the number of birthday greetings and "likes" were big culprits. Unprecedented access to other people's photos also triggered emotional pain and resentment.

Photo tagging is another way in which people allow for play with traits and characteristics on facebook. A lot of quizzes in fact, on facebook itself, invite people to view what kind of a 'facebook personality' they are. But it is exploiting the idea that people are always seeking newer ways of seeing themselves, one always likes to read about an interpretation that is made about them.

Vladimir Rinskii in 'The influence of the internet on active social involvement and the formation and development of identities' (Russian education and society, Vol-52, No.8, August 2010, PP. 11-33) does and interplay of classical psychoanalytic understanding of identity and identity as its viewed on the internet to comment on the changing structure of individual and social identity formation.

He starts off by explaining the basics of identity formation via Freud and ties that up with the promise that the internet provides and the avenues that are maid available to initiate uses for identity exploration. 
The internet today according to him serves the need of belongingness of an individual where in the individual has a sense of his own self by way of his social interactions with others. A failure to find an identity reflection would have led to rage and unconscious aggression but because of the large user database of the internet, no one is subjected to that. He uses the philosophical conceptions of structurism and post modernism about written text as a reliable means to register human consciousness. Thereby providing the idea of today's 'inter text', which is a series of quotations cut and paste together to form a new meaning. With no author to claim the meaning and numerous readers to provide new meaning to the text, a fluidity of form is seen in the text which he equates with the dynamic consciousness off modern man.

"The most important thing that is disappearing is the difference between what is real and what is imagined." Rimsky, who is from the sociology department at The Information Science for Democracy Foundation or INDEM foundation, writes about the shared activities of online selves even as offline selves don't interact. The virtual environment impacts the meaning making behind the messages shared. However, social characteristics remain intact to that each individual still formulates an identity, a membership of the group, and accepts its values and his role in the group. An ill formed identity shall be rejected even in such groups.

I turned to Erik H. Erikson's own writing on 'Adolescence' in his book 'Identity Youth and crisis' (W. Norton and company, 1968).

He describes the identity crisis during adolescence as the search for a moratorium or the state of actively exploring different identities, but not making a commitment. "beset with the physiological revolution of their genital maturation and the uncertainty of the adult roles ahead, (they) seem much concerned with faddish attempts at establishing an adolescent subculture with what looks like a final rather than a transitory, or in fact, an initial identity formation. They are often morbidly preoccupies with what they appear to be in the eyes of others," he wrote.

He writes about the rush of volition every adolescent craves to feel and the way this is played out is often in occupational choices. They play with free will and rebel so as to tow the line and test the limits of their own selves more than take liberties. This is also that phase in life where he suggest, past conflicts are resolved to create a more stable adult future and dependant on the level of freedom one is given, adoloscents are able to fins a way of 'self therapy'.

Erikson writes of the peculiarity of love at this stage as conversational and less to do with sex, the lover is more of a partner who can be mirrored, idealised or devalued, but mostly someone to bounce off your ideologies as the adolescent rapidly takes up and abandons several. We must be careful not to pathologise too quickly the adolescent journey, Erikson also talks about this nature as carried forward into adulthood by people with a creative bend of mind as they produce art and constantly experiment. 


\section{Lonely Together: The Psychological Divide Due To Social Networking Sites}

Dr Himanshu Tyagi, a psychiatrist at West London Mental Health Trust, said that, "It's a world where everything moves fast and changes all the time, where relationships are quickly disposed at the click of a mouse, where you can delete your profile if you don't like it and swap an unacceptable identity in the blink of an eye for one that is more acceptable. "If you can't see the person's expression or body language or hear the subtle changes in their voice, it shapes your perceptions of the interaction differently,' Dr Tyagi said, "A session in front of the computer was also likely to create an altered perception, a dream-like state, an unnatural blending of their mind with the other person - something that rarely happens in real life. The new generation raised alongside internet is attaching an entirely different meaning to friendship and relations, something we are largely failing to notice.it may be quite different for teens and children who cannot imagine a world where you can't go online to talk and apply the same principles to realworld interpersonal communications, mostly to a dysfunctional outcome."

People with lower self-esteem tend to be much more concerned with what others post about them on Facebook, while users with higher self-esteem spend more effort on adding information to their personal profiles on the social network, said Sundar, Distinguished Professor of Communications and co-director of the Media Effects Research Laboratory, Penn State. People with both high and low self-esteem spend time crafting their online personas on Facebook, but choose different paths in that construction. Individuals with higher self-esteem have a greater sense of agency and spend more time adding information about their family, education and work experience to their profiles.

A study conducted by The University of Gothenburg in Sweden surveyed 335 men and 676 women (average age 32) to help determine the link between self-esteem and Facebook usage. A significant negative relationship between the two was uncovered (as Facebook interaction increased, self-esteem decreased), though the main difference was between genders. Women who used Facebook were apt to feel less happy and content with their lives.

A 2009 study published in the journal Cyberpsychology, Behavior and Social Networking looked at 63 Cornell students who were divided into three groups in a social media lab. One group sat at computers that depicted their Facebook profiles, another group sat at computers that were turned off, and the last group sat at turned-off computers with mirrors propped up next to them. Students with the computers logged onto Facebook were allowed to spend three minutes exploring and editing their profiles. After three minutes, all participants were given a questionnaire that measured self-esteem using the Rosenberg Self-Esteem scale. When researchers compared the group with a mirror and no Faceboook access to the group with no Facebook access or a mirror, no elevation in self-esteem was reported. However, a drastic rise in self-esteem was found in the group that spent time on Facebook; those who also edited their profiles had the highest self-esteem in the entire study.

In order to evaluate the effect social media on mental health one must first understand which mental health concerns and disorders are being attributed to Facebook usage. Bipolar disorder is characterized by mood swings that go from periods or depression to highs of mania. There has 
been some research that has indicated many confirmatory connections between activities on Facebook and symptoms of depression. (Rosen 2013) An example of this can be found in the some Facebook actions such as making negative comments about posts or pictures can cause negative feelings, as can "unfriending". Unfriending is the action taken when someone chooses to no longer be connected to another person on Facebook. This action, according to Bevean, Pfyl, and Barclay (2012), is shown to be very strongly related to negative emotional responses. It can be similar to losing a friend in the offline world.

Twenge and Campbell (2009) discuss what they call a narcissism epidemic and document its escalation over the past twenty years. This escalation is by some attributed to the new forms of technology that exist, especially social networking sites, the most popular of which is Facebook. When the activities in which a person takes part on Facebook are examined one can really see the connection between narcissism and social media sites. Facebook users for example post status updates, and pictures of their lives seeking comments or "likes" from their Facebook "friends", and they too comment and like those friends' statuses. Buffardi and Campbell (2008) are at the forefront of research linking the narcissistic personality disorder and Facebook usage.

According to Valkenburg, Peter, and Schouten (2006) the frequency with which adolescents use the social networking sites influences their social self esteem and well being. It can have a positive impact on their social self esteem, but more commonly it has a negative impact. (Gangadharbatla,2008) Facebook creates an atmosphere which breeds collective self esteem. There is a fear that collective self esteem is related to social networking sites which can negatively affect youth.

In an article 'Facebook Generation' Faces Identity Crisis (medical news today.com), the correspondent writes, 'A generation of Internet users who have never known a world where you can't surf on-line may be growing up with a different and potentially dangerous view of the world and their own identity, according to a warning delivered to the Annual Meeting of the Royal College of Psychiatrists.

\section{CONCLUSION}

The media is rapidly evolving and I have always found it interesting to watch how it changes society. Why I chose to study facebook was because not only was it the most hyped, the most recent technological tool of communication but also it's form is that of convergence of audio, video, textual, public, private etc and it provides platform for any kind of conversation (except oral or face to face) to occur.

A hugely popular Youtube video by the name of 'facebook song' showcases through song the reasons for such an addiction as the control it provides over interactions. The lyrics are as follows,

"There's not much that separates me, from the other guy. But when I log in, I begin to live. There's an online world, where I am king. Of a little website dedicated to me. 
Facebook, I am hooked.I am hooked to facebook.

If the internet crashed, all across the land. Or my account was deleted by demand. Id carry around a picture of my face, And a summary of me typed out on a page.

Its more than I want, Its more than I need, id shrivel up and die, Without my many feet.

Facebook, I am hooked. I am hooked to facebook.”

Winston Churchil had once said, "we shape our buildings and then they shape us" similarly, today we can say, We make our technologies and then they make us. So of every technology we must ask, does it serve our human purpose and keep that purpose as primary. Facebook gives us too much too soon but it is allowing us access to us, it is a tool. It is as asinine as you make it.

Thus, the sense of satisfaction that comes along the internet indulgences feeds a negative cycle where more time spent online means less real social contact and less physical activity, increasing the vulnerability to psychological disorders. Hence, overuse of internet can genuinely restrain an individual from experiences in life, their academic/professional performance, and social and psychological well being. Since this is a social web, therefore safety here depends a great deal on the way we behave towards one another.

Deleting a Facebook account is no small feat either. As soon as you muster up enough courage to leave behind all the friends and the online life you have cultivated for yourself for no matter how much time, facebook makes it difficult for you to leave. As you select the delete account option, it immediately launches into question mode, it first asks "are you sure" then asks you to specify why and gives a range of options, if you select any option it gives you possible solutions. For example, it would ask, "

Reason for leaving (Required):

I don't feel safe on Facebook.

I get too many emails, invitations, and requests from Facebook.

I don't find Facebook useful.

I have a privacy concern.

I spend too much time using Facebook.

I don't understand how to use Facebook.

My account was hacked.

This is temporary. I'll be back.

I have another Facebook account.

Other 
Please specify And for any of these responses, it redirects you to a page that gives possible security related or other solutions. It also posts the pictures of your closest friends on that page with captions like, 'XYZ will miss you', 'send a message to XYZ'.

The media is rapidly evolving and I have always found it interesting to watch how it changes society. Why I chose to study facebook was because not only was it the most hyped, the most recent technological tool of communication but also it's form is that of convergence of audio, video, textual, public, private etc and it provides platform for any kind of conversation (except oral or face to face) to occur.

Facebook has become an efficient tool in this form of identity exploration in which users actively engage in the social discourse of instant validation (i.e.publishing one's image in hopes of receiving instant and positive feedback). While instant validation can occur both online and offline, it is important to explore whether Facebook has changed the way people engage in that behaviour.

An online identity is anything and everything we want it to be. By viewing our own profile we see what others see and begin to compare our self-image to that which we see. Then we can change the profile to match our self-image more clearly. The profile changes, but we do not. Or do we? Does self-realization occur when we view our life through another's perspective? And does that realization cause us to change attributes of our real identity? Or does it simply cause us to make false statements on our profile in order to allow ourselves to remain as we are? Is the profile real? Does the profile become us? Or do we become the profile? The answer is both. We change aspects of our profile and identity in order to create a new self. But the window for viewing is limited. Our personal information is limited to: sex, relationship status, sexual preference, political and religious views, activities, interests, favorite music, favorite TV shows, favorite movies, favorite books, favorite quotations, education, and work. Personality is beginning to be defined by the set of information that exists on our profile, which we use to judge a person based on a wide variety of aspects.

First impressions are now different when taken from Facebook. Facebook is now an artifact that represents our personalities, replacing such artifacts as diaries and journals, which were used to record people's personality before the internet and online profiles. Diaries and journals are a personal and unedited view into a private world. Facebook profiles are public and editable. Therefore, they often offer a skewed view of who we are. Due to Facebook's nature the content is easily changed and we can change to match it.

It is evolving with us, first, the focus of the application experience has shifted from user profiles to user activity. Users can now express themselves in many ways other than textual selfdescription. They can write status updates, short notes or blog entries, post links, photos, videos, etc. The landing page for the site displays a news feed with all your friends recent activity where you can comment and respond directly. In this way, users can have lots of conversations and interactions without ever navigating to someone's profile page. On the profile page itself, the selfdescriptive information has been replaced with a news feed of that user's activity. In short, the means of self-presentation on Facebook is shifting from that of static representation to more dynamic, contextual action. 
But the danger is when people start to look at the website as more than just an extension of life. A lot of people have started using the word addiction with facebook. its addictive games, posts les people spend hours online without getting to know how time passed. They build up their online lives with such care and precision that their offline lives begin to suffer. People are lonely, the network is seductive. But if we are always on, we may deny ourselves the reward of solitude.

Winston Churchil had once said, "we shape our buildings and then they shape us" similarly, today we can say, We make our technologies and then they make us. So of every technology we must ask Does it serve our human purpose and keep that purpose as primary. Facebook gives us too much too soon but it is allowing us access to us, it is a tool. It is as asinine as you make it.

What is truly remarkable to me during the process of this research was the unexpected inward journey I began to take which brought new depths to my knowledge and if this isn't a marker of just how much facebook has begun to change us and bring about the opportunity of a look at the self, then I don't know what is.

We are delving deeper and deeper into a technological realm, with no understanding of what it is doing to us. Thus the scope for further studies is immense and the field of psychology also needs to take notice of such areas of study because the generation growing up 'tethered' right now is going to bring with it understandings and dissatisfactions from this realm and in order to fully embrace the human experience, psychology must keep up with technology.

\section{REFERENCES:}

Bevan, J. L., Pfyl, J., \& Barclay, B. (2012). Negative emotional and cognitive responses to being unfriended on Facebook: An exploratory study. Computers in Human Behavior.Bipolar disorder. (n.d.). Retrieved from http://www.mayoclinic.com/health/bipolar disorder/DS00356

Denti, L., Nilsson, I., Barbopoulos, I., Holmberg, L., Thulin, M., Wendeblad, M., ... Davidsson, E. Sweden's Largest Facebook Study: A Survey of 1,000 Swedish Facebook Users. Gothenburg Research Institute, April 2, 2012.

Facebook -- with or without Google -- will destroy the world as we know it, www.lyndonplumber.com, Lyndon 2010, http://lyndonplumber.typepad.com/blog/2010/11/facebook-with-or-without-google-willdestroy-the-world-as-we-know-it-1.html

Gonzales, A., \& Hancock, J. (2011). Mirror, Mirror on my Facebook Wall: Effects of Exposure to Facebook on Self-Esteem. Cyberpsychology, Behavior and Social Networking, 14, No. 1-2. DOI: $10.1089 /$ cyber.2009.0411

Jean-Jaques Rousseau (1987), The Basic Political Writings Of Jean-Jaques Rousseau (Indianapolis: Hackett Publishing Company, Inc.).

http://www.wbur.org/2013/02/20/facebook-perfection 


\section{Lonely Together: The Psychological Divide Due To Social Networking Sites}

Mehdizadeh, S. (2010). Self-presentation 2.0: Narcissism and self-esteem on Facebook. $\begin{array}{llll}\text { Narcissistic personality disorder. (n.d.). } & \text { Retrieved from }\end{array}$ http://www.mayoclinic.com/health/narcissistic-personality-disorder/DS00652.

On Being Bored, On Kissing, Tickling \& Being Bored; Psychoanalytical Essays on the Unexamined Life, Howard University Press, 1993.

Pg. 20, Introduction: Alone together, Alone together: Why we expect more from technology and less from each other, Sherry Tukle, Published by Basic Books, New York, 2011

Pg. 34, The capacity to be alone, D.W. Winnicot, Maturational Processes, Karnac Books, 1958.

Pg. 34, The capacity to be alone, D.W. Winnicot, Maturational Processes, Karnac Books, 1958.

Pg. 14, Introduction, In Pursuit of Silence: Listening for meaning in a world of noise, George Prochnik, Doubleday, 2010

Pg. 16, Introduction: Alone together, Alone together: Why we expect more from technology and less from each other, Sherry Tukle, Published by Basic Books, New York, 2011

Pg. 1, Introduction: Alone together, Alone together: Why we expect more from technology and less from each other, Sherry Tukle, Published by Basic Books, New York, 2011

Pg. 156, Ch. 8, Always On, Alone together: Why we expect more from technology and less from each other, Sherry Tukle, Published by Basic Books, New York, 2011

Pg. 159, Ch. 8, Always On, Alone together: Why we expect more from technology and less from each other, Sherry Tukle, Published by Basic Books, New York, 2011

Pg. 164, Ch. 8, Always On, Alone together: Why we expect more from technology and less from each other, Sherry Tukle, Published by Basic Books, New York, 2011

Pg. 179, Ch. 9, Growing up Tethered, Alone together: Why we expect more from technology and less from each other, Sherry Tukle, Published by Basic Books, New York, 2011

Pg. 254, Ch. 13, Anxiety, Alone together: Why we expect more from technology and less from each other, Sherry Tukle, Published by Basic Books, New York, 2011

'Performing identity on facebook', http://www.davidroedl.com', David Roedl, 2009, http://www.davidroedl.com/2009/02/28/performing-identity-on-facebook/

'Performing identity on facebook', http://www.davidroedl.com', David Roedl, 2009, http://www.davidroedl.com/2009/02/28/performing-identity-on-facebook/

Pg. 16, The influence of the internet on active social involvement and the formation and development of identities, Vladimir Rimskii, Russian education and society, Vol52, No.8, August 2010.

"The Effects of Facebook on the Self Esteem of Teenage Girls" StudyMode.com. 022012. 2012. $022012<$ http://www.studymode.com/essays/The-Effects-Of-Facebook-On-The917204.html>.

Valkenburg, P.M., J. Peter, and A.P. Schouten (2006), "Friend Networking Sites and Their Relationship to Adolescents' Well Being and Social Self-Esteem," CyberPsychology \& Behavior, 9 (5), 584-590. 